\title{
YRJÖ HAILA
}

\section{KAUPUNKIEN SAMANLAISUUS}

\author{
JA ERILAISUUS
}

Kaupungeista on moneksi. Toistakaamme mielessämme muutaman suomalaisen kaupungin nimet. Niiden tuottamat mielikuvat ovat hyvin erilaisia. Vertailuun sisältyy kuitenkin ilmeinen ongelma: Mielikuvia määrittävät ensisijaisesti välittömiin kokemuksiin ja havaintoihin perustuvat seikat, joilla ei välttämättä ole paljoakaan tekemistä eri kaupunkien olennaisten piirteiden kanssa.

Mitkä ovat kaupunkien olennaisia piirteitä? Jossakin hyvin yleisessä ja abstraktissa mielessä kaikki kaupungit ovat yhtä ja samaa. Ne ovat ihmisten sosiaalisen yhteiselon kokoumia, organisoitumisen perustoja ja kulttuurin kasvualustoja. Max Weber esimerkiksi korosti tätä seikkaa ja pyrki jopa luomaan kaupunkien perustyypeille yleispätevät luonnehdinnat. ${ }^{1}$ Nämä olivat ideaalityyppejä, kuten Tapani Hietaniemi Weberin teokseen kirjoittamassaan esittelytekstissä korosti, mutta juuri sen ansiosta Weberin esittämä jäsennys auttaa edelleen ymmärtämään erilaisten kaupunkien taustalla olevia eroja. Jokaisen kaupungin synnyllä on omanlaatuisensa perusta. Taustojen vaihtelu - satamakaupunki, teollisuuskaupunki, hallintokaupunki, kauppakaupunki, varuskuntakaupunki ja niin edelleen - eriyttää myös suomalaisia kaupunkeja toisistaan.

Syntyhistorioiden vaikutukset ovat kuitenkin liudentuneet. Georg Simmel esitti tästä selvät viitteet vuosisata sitten kirjoituksessaan modernista suurkaupungista. ${ }^{2}$ Arto Noro toteaa Simmelkokoelman esipuheessaan (s. 20): "Sen [kaupunkiesseen] lopussa Simmel järjestää lukijalle yllätyksen osoittamalla, että onkin kyse suuremmista ja syvällisemmistä asioista kuin vain sopeutumisestamme elämään suurkaupungissa.” Nimittäin, Simmelin omin sanoin (s. 46): Suurkaupunki osoittautuu yhdeksi niistä suurista historiallisista muodostelmista, joissa vastakkaiset, elämää sykkivät virtaukset saavat yhtäläiset oikeudet olla ja kehittyä.” - Voimme olettaa, että vastaavanlainen muutoksen hyöky on sittemmin ulottunut koskemaan modernia urbaania elämäntapaa kaikkialla, myös pienissä kaupungeissa (ainakin johonkin rajaan asti).

Tämän numeron useissa kirjoituksissa arvioidaan sitä, millaisia samankaltaisuuksia on erilaisten suomalaisten kaupunkien päätöksenteon asetelmissa ja ehdoissa. Kaupunkien kehittämiseen liittyvät ongelmat ovat samankaltaisia, kaupunkien koosta riippumatta, ja tilanteet muuttuvat nopeasti. Tuntuu siis tarpeelliselta pohtia päätöksenteon "ketteryyden" tai "notkeuden" ehtoja. Millaisia ovat tämän yhteisyyden paikalliset ominaispiirteet?

Kiinnostavan näkökulman erilaisten kaupunkien vertailulle tarjoaa ajatus, että kaupungit ovat saaneet hahmonsa eli organisoituneet epälineaaristen dynaamisten vuorovaikutusten seurauksena. Chuck Dyke on kehittänyt kaupungin ja biologisen organismin välistä analogiaa taloudellisten vuorovaikutusten perustalta. ${ }^{3}$ Sekä organismit että kaupungit ovat aineenvaihdunnallisia kokonaisuuksia. Vaikka erilaiset organismit poikkeavat rakenteeltaan tavattomasti, aineenvaihdunnan periaatteet ovat kaikilla samat: energiaa (ravintoa) on saatava ulkopuolelta, energia on saatava elimistössä käyttöön siellä missä sitä tarvitaan, ja kuona (jätteet) on eritettävä kehon ulkopuolelle. Vastaavasti kaupungit 
elävät aineenvaihdunnassa ympäröivien alueidensa kanssa. Kaupungin edellytykset luo materiaalisen vaurauden gradientti, joka synnyttää kaupankäynnin virtoja ja suotuisissa olosuhteissa muuttuu organisaatiota luovaksi voimaksi (Dyken termit ovat'gradient-tracking' ja 'organization-promoting').

Analogiapäättely on hedelmällinen tapa siirtää tietoa valistuneen arvauksen muodossa tutusta tuntemattomaan. Dyken vertailussa "tuttu" on biologinen organismi, "tuntematon" on organismiin rinnastuva olio kuten kaupunki. Organismi on ilmeisen jäsentynyt kokonaisuus, joka on saanut hahmonsa itsestään, ilman rakennuspiirustuksia. Analogian lähtökohdaksi hyväksytään olettamus, että organismi ja kaupunki ovat dynaamisesti merkityksellisellä tavalla samankaltaisia.

Teoreettisen fysiikan taustan omaava Geoffrey West esittää tuoreessa teoksessaan ${ }^{4}$ täsmällisempiä kvantitatiivisia rinnastuksia organismien ja kaupunkien välillä. Keskeinen käsite on skaala, joka kattaa sekä koon että organisoitumisen periaatteet. Westin teoreettinen olettamus on, että sekä organismit että kaupungit ovat komplekseja, sopeutuvia ja itseorganisoituvia kokonaisuuksia ja että itseorganisoituvilla systeemeillä on koosta riippumattomia skaalan tuottamia rakenteellisia säännönmukaisuuksia. Ilmiön tekninen nimitys on "itse-samankaltaisuus" (self-similarity). Taustan muodostavat organismien rakennetta kuvaavat allometriset säännöt, jotka on tunnettu 1900-luvun alkupuolelta lähtien. Varhaisin tunnettu sääntö koski metabolian nopeuden (eli kuinka paljon ravintoa organismi tarvitsee aikayksikköä kohden) ja ruumiin painon suhdetta, jota matemaattisesti kuvaa niin sanottu potenssilaki (power law): riippuva muuttuja määräytyy riippumattomasta muuttujasta korotettuna potenssiin, joka on eri suuri kuin yksi. Organismien metabolian nopeus riippuu ruumiin painosta korotettuna potenssiin 3/4. Toisin sanoen eri kokoisia eläimiä verrattaessa niiden koko kasvaa nopeammin kuin metabolian nopeus: esimerkiksi norsu tarvitsee energiaa "vain" kolme kertaluokkaa (eli 1,000 kertaa) enemmän kuin hiiri, vaikka se on hiirtä neljä kertaluokkaa (eli 10,000 kertaa) suurempi. ${ }^{5}$

West kollegoineen on eritellyt allometristen sääntöjen perustana olevia mekanismeja. Esimerkiksi metabolian voi johtaa energetiikasta, verisuoniston rakenteen taas nestevirtausten dynamiikkaa määrittävistä periaatteista (ns. Rayleigh-luku), ja niin edelleen. Itseorganisoituviin ja metabolian ylläpitämiin systeemeihin pätee energeettinen tasapainotilinpidon periaate: sisään tulee ja ulos lähtee identtinen määrä energiaa (koska energia ei häviä). Aineenvaihdunta, metabolia tarjoaa liikevoiman organismin rakentumiselle. ${ }^{6}$

West esittää kaupunkiteoreettisena interventionaan, että moniin kaupunkien sosiaalis-taloudellisiin piirteisiin voidaan soveltaa rakenteeltaan samankaltaista allometristä suhdetta kuin organismeihin. Kun väkiluku on kaupunkien kokoa kuvaava muuttuja (riippumaton muuttuja), seuraavat piirteet (riippuvat muuttujat) osoittavat säännöllistä potenssilakia noudattavaa suhdetta: palkkataso Yhdysvaltojen kaupungeissa; korkeasti koulutettujen asukkaiden määrä Yhdysvaltojen kaupungeissa; patenttien määrä Yhdysvaltojen kaupungeissa; rikollisuus japanilaisissa kaupungeissa; ravintoloiden määrä hollantilaisissa kaupungeissa; ja BKT ranskalaisissa kaupungeissa. ${ }^{7}$

Jännittävä piirre Westin kollegoineen kokoamissa suhteissa on, että potenssilain eksponentti on 1.15 eli suurempi kuin yksi. Suhde on supralineaarinen (supralinear): näiden sosiaalis-taloudellisten piirteiden arvot kasvavat nopeammin kuin lineaarisesti kaupungin koon kasvun myötä. Mitä paremmin menee, sen paremmin menee. - Mutta toki kaupunkien kasvun "supralineaarisuus" on havaittu kvalitatiivisesti jo aiemmin. Simmel totesi ilmiön seuraavasti: "Samalla lainalaisuudella kuin omaisuus karttuu - kun tietty raja ylittyy, omaisuus kasvaa yhä nopeammin aivan kuin itsestään - kaupungin taloudelliset, henkilökohtaiset ja henkiset suhteet laajenevat ja sen näköpiiri ja aatteellinen vaikutusalue kasvavat geometrisessa suhteessa, kun tietty raja ylittyy."

$* * * * * *$

Westin kokoamat aineistot osoittavat, että organismien ja kaupunkien rinnastus (analogia) on vähintäänkin kiinnostava. Hänen esityksensä on kuitenkin tilastollinen ja käyttää jokaista kaupunkia yhte- 
nä kvantitatiivisen suhteen havaintoyksikkönä. Tässä ei tietenkään ole "sinänsä" mitään epäilyttävää, mutta olettaisin, että erilaisten kaupunkien erilaiset kehityskulut peittyvät tilastollisen suhteen sisään.

Oman aikuisikäni kaupunkeja ovat olleet Helsinki, Pori, Tampere ja Riihimäki, tässä järjestyksessä. Niiden historiat ovat hyvin erilaiset. Riihimäki on ylivoimaisesti nuorin. Riihimäelle muodostui työasema ja asutusrypäs Helsinki-Hämeenlinna-radan rakennustöiden yhteydessä. Riihimäen kirjaston kokoama historiallisten vinjettien sarja kuvaa kaupungin taustan 1850-luvulla seuraavasti: "Hausjärven pitäjän Karan, Ryttylän ja Herajoen kylien rajojen yhtymäkohdan tienoilla sijaitsee lähes asumaton soinen seutu, jossa on vain joitakin Karan ja Ryttylän kartanoiden torppia. Rautatienrakennuksen alettua paikalle perustetaan työasema ja majoitetaan radanrakentajia. Asema saa nimekseen Riihimäki."

Helsinki ja Pori ovat vanhimmat. Pori muodostui kaupungiksi Juhana-herttuan päätöksellä (1558), mutta sitä edelsivät Kokemäenjoen suun kauppakeskuksina Teljä nykyisen Kokemäen sijoilla sekä Ulvila. Pohjanlahden rannikolla maa kohoaa ja merenranta siirtyy sen myötä ulommaksi: Pori on osa satamakaupunkien jatkumoa. Helsingin perusti Kustaa Vaasa Vantaanjoen suulle (1550), mutta se sai vajaat vuosisata myöhemmin uuden alun nykyisen Kruunuhaan tienoilla.

Tampere syntyi Kustaa III:n päätöksellä harvaan asutulle metsäalueelle Tammerkosken laitamille (1779). Kustaan tavoite oli oletettavasti kasvattaa kruunun verotuloja. Tampere kehittyi merkittäväksi teollisuuskaupungiksi kuitenkin vasta Venäjän vallan aikana; se oli "Venäjän talouspolitiikan luomus, tarkemmin sanottuna suurvaltojen kilpailun ja protektionismin tulos". ${ }^{10}$

Helsinki monimuotoistui muututtuaan Suomen pääkaupungiksi 1800-luvun alussa. Pori ja Tampere ovat molemmat raskaan teollisuuden kaupunkeja, joskin Porilla satamakaupunkina on myös vahva kauppakaupungin tausta. Kuten Porin historiainfossa todetaan: "Itsenäisyydenajan Suomessa Pori on ollut merkittävä, nopeasti kasvava suurteollisuuden ja satamien kaupunki. Rosenlew, Outokumpu, Rauma-Repola, Kemira ja muut teollisuuslaitokset tarvitsivat runsaasti uutta työväkeä, kaupunki kasvoi nopeasti." ${ }^{11}$ Myös Riihimäki kasvoi edullisten liikenneyhteyksien ansiosta kohtuulliseksi teollisuuskaupungiksi 1900-luvun alussa. Merkittäviä laitoksia olivat Riihimäen Saha (Paloheimo Oy; 1904) sekä Riihimäen Lasitehdas (1910).

Suomalaisten kaupunkien lähihistoriaa määrittää kaksi toisiinsa kietoutunutta yhteiskunnallista murrosta:"suuri muutto" eli väestön laajamittainen muutto maaseudulta kaupunkeihin (tai siirtolaisiksi Ruotsiin) sekä tuotannon rakennemuutos yleisnimeltään"savupiipputeollisuuden kriisi”. Edellisen jäljet ovat näkösällä kaikissa asuinkaupungeissani: yksityisauton varaan perustetut lähiöt Helsingissä ja Tampereella sekä anonyymien elementtitalojen ryppäät Porin ja Riihimäen keskustojen tuntumassa. Suuren muuton seurauksena kaupunkien väkiluku kasvoi, ja ilmapiiri oli optimistinen.

Tuotannon rakennemuutos sen sijaan toteutui asuinkaupungeissani eritahtisesti. Helsinki vältti suuremmat haitalliset seuraukset kaiketi kokonsa ja monipuolisuutensa tarjoamien sopeutumismahdollisuuksien ansiosta. ${ }^{12}$ Teollisuuskaupungit Pori ja Tampere sen sijaan joutuivat murroksen seurauksena suuriin vaikeuksiin. Pori oli tosi tiukoilla. Usko savupiipputeollisuuteen istui kaupungissa lujassa vielä kun sen edellytykset olivat kadonneet. Porin poliittista ilmapiiriä hallitsi pitkään duunarikaupungin leima. Usealta taholta kuulemani tarinan mukaan Porille tarjottiin yliopistoa, mutta sitä ei otettu vastaan koska sen pelättiin muuttavan kaupungin väestöpohjan porvarilliseksi.

Janne Toivonen kuvaa tilannetta vauhdikkaassa henkilökohtaisesti sävyttyneessä historiassaan seuraavasti:"1990-luvun alussa Pori oli tienhaarassa. [...] Aikaa leimasi sivusta seuraaminen. Perusteollisuuden työpaikat koottiin Suomessa muutamaan yksikköön tai vietiin Itä-Eurooppaan ja Aasiaan. Porissa katseltiin, kun kaupunkia hallinneet tutut työnantajat laittoivat lappuja luukulle.”1990-luvun alkupuolella tilanne alkoi kuitenkin muuttua,"Vuoteen 1993 tultaessa päätä oli hakattu seinään riittävän kauan, oltiin valmiita nöyrtymään." 13

Myös Tampere ajautui vaikeuksiin, mutta selvisi kumminkin vähemmällä kuin Pori. Tampere on Suomen eteläisen sisämaan tärkein liikennekeskus ja Pohjoismaiden suurin sisämaakaupun- 
ki. Monipuolisuus ja sen tuottama avara näkemys auttoivat. Lisäksi yliopiston sekä teknillisen korkeakoulun (myöhemmin teknillisen yliopiston) vaikutus edisti luovaa toimeliaisuutta ja lievensi rakennemuutoksen jyrkkyyttä.

Riihimäen tarina on tässä joukossa surkein. Teollisuutta oli syntynyt, ja tuotantorakenne oli näennäisesti monipuolinen, mutta Riihimäki oli pahasti riippuvainen Paloheimon suvun johtamista liiketoimista ja niiden menestyksen aaltoilusta. ${ }^{14}$ Kun lasitehdas alkoi hiipua 1970-luvulla, kaupunki oli tapahtumakulkujen armoilla. Lasitehdas liitettiin Ahlström-konserniin vuonna 1990 ja ajettiin lopullisesti alas.

Joseph Schumpeterin luoma käsite 'luova tuho' kuvaa kapitalismin dynamiikan näkökulmasta tuotantorakenteen muutosten seurauksia. ${ }^{15}$ Luova tuho ilmenee silloin, kun kannattamattomaksi ajautunut toiminta-ala häviää ja tarjoaa tilaa uudelle, innovatiivisemmalle ja tuottavammalle toimintasektorille. Tuhon "luovuus" on näin ollen suhteellista. Tuho on myös tuhoavaa.

Nelikko Helsinki-Pori-Tampere-Riihimäki tarjoaa mahdollisuuden arvioida "luovan tuhon" ilmenemistä erilaisissa suomalaisissa kaupungeissa, arvauksen omaisesti ja mutkia oikoen.

- Helsingissä tuholla ei kaiketi ollut koko kaupungin taloudessa näkyviä seurauksia; oletan, että tuotantoalojen ja toimeliaisuuden monipuolisuus on pitänyt yleiskuvan jokseenkin vakaana, vaikka yksittäisillä aloilla epäilemättä tapahtui vaihtumaa.

- Porissa tuho oli hetkellisesti lamauttava, mutta kaupunki selvisi ahdingosta pitkähkön pyristelyn jälkeen. Kaupungin johdossa lienee toiminut riittävän määrätietoisia ja näkemyksellisiä poliitikkoja. Ensisijainen veikkaukseni on pitkäaikainen kaupunginjohtaja (1975-2004) Martti Sinisalmi, jonka panosta myös Janne Toivonen arvostaa.

- Tampereella tuho oli pääpiirteissään luova, kaiketi monipuolisen taloudellisen vireyden sekä yliopiston ja teknillisen korkeakoulun ansiosta.

- Riihimäellä tuho oli tuhoava. Riihimäki on edelleen minulle arvoitus: se on kovin pieni liikenteellisesti edulliseen sijaintiinsa nähden. Yksinkertaisin tulkinta asetelman taustasta on pienen koon tragedia: vähäisetkin virheet tai epäonnen iskut ovat suhteellisesti merkityksellisiä, ja hetkelliset pakot nousevat hallitseviksi. Osa Riihimäen pienuuden tragediaa on ollut vahva riippuvuus Paloheimon mahtisuvusta, joka ei ole kyennyt järjellisesti johtamaan moniaalle haarovaa liiketoimintaansa.

Riihimäen kohtalo osoittaa kylläkin myös sen, että pelkät hyvät liikenneyhteydet eivät ratkaise kehittymisen ehtoja. Olennainen on yhteyksien laatu. Maantieliikenteen volyymin ja suhteellisen merkityksen kasvu on luultavasti murentanut rautateiden aiemmin tarjoaman sijaintiedun. Riihimäen sivuitse kulkeva moottoritie Helsingistä Tampereelle otettiin käyttöön 1990-luvulla, mutta moottoritien liittymiin ei synny asutusta, kauppaa tai teollisuutta (abc-asemia lukuun ottamatta).

Olisiko kulttuurista kaupunkien uudistumisen turvaajaksi? Pelkään, että'kulttuuri' on liian yleisluonteinen termi soveltuakseen arvioinnin perustaksi. Sitä paitsi kulttuuri elää - tai kuihtuu - politiikan kentän määräämillä ehdoilla. Pienten paikkakuntien ja maakuntien mittakaavassa kulttuurin itsenäisyyttä uhkaavat aina poliittiset intohimot. Erno Paasilinna kuvasi asetelmaa lainaten Anton Tsehovin aforismia: "Kaikista sietämättömimpiä ihmisiä ovat maakunnalliset kuuluisuudet."16 _ Toisin sanoen, "kulttuuri" tarjoaa kasvualustan sietämättömille maakunnallisille kuuluisuuksille.

Mitä pienempi paikkakunta, sitä ailahtelevampia ovat kulttuurin ehdot. Kuitenkin juuri pienillä paikkakunnilla kulttuuri tarvitsisi pitkäjänteisen ja vakaan perustan. Helsingillä ei ole tässä mielessä ollut ongelmia. Pori on vuosikymmenten mittaan saavuttanut jazz-juhlien ja taidemuseon ansiosta vakaan valtakunnallisen aseman. Tampere on tunnettu teatterikaupunki ja vahvistuu musiikkikaupunkina, joskin joillakin muilla kulttuurin alueilla, esimerkiksi kuvataiteessa, se on kokoaa pienempi. Entä Riihimäki? - Riihimäki on viime vuosien teatteri-ihme, jonka vähäisillä voimavaroilla elävä kaupunginteatteri on ollut useita kertoja kutsuttuna Tampereen teatterikesään vierailijaksi ja joka nimitettiin vuoden teatteriksi 2017. Mutta teatteri on juuri se kohde, jonka 
rahoitusta kaupunki on samoina vuosina toistuvasti leikannut. Riihimäen taidemuseo elää vastaavanlaisessa paineessa: Museon ytimen muodostaa lahjoituksena saatu Tatjana ja Pentti Wähäjärven kokoelma (1993), johon sisältyy joukko 1900-luvun alkuvuosikymmenten merkittäviä suomalaisia taideteoksia. Kaupungin johdossa harkitaan tämän tästä museon lakkauttamista tai yhdistämistä muiden museoiden kanssa.

Kaupunkien omalaatuiset kehityskulut osoittautuvat kylläkin tarkemmassa katsannossa tärkeiksi, mutta myös Geoffrey Westin skaalatarkastelut tarjoavat jännittävän kehyksen neljän asuinkaupunkini vertailulle. Kaupungin koko on ilmiselvästi vaikuttanut siihen, kuinka "luovia" tai "tuhoavia" savupiipputeollisuuden ahdingon seuraukset ovat olleet.

Jatkan vielä biologista analogiaa: Voisi ajatella, että suuressa monimuotoisessa kaupunkikokonaisuudessa (Helsinki, Tampere) on enemmän sijaa tiettyjen nimettyjen toimintojen tehokkuutta (mielekkyyttä) lisääville valinnan prosesseille kuin pienessä (Pori, Riihimäki). Se, millaiset mekanismit tämän kaltaista "valintaa” voisivat edistää tai haitata, on tietenkin kokonaan toinen kysymys.

\section{VIITTEET}

1. Max Weber, Kaupunki. Vastapaino 1992. Tapani Hietaniemen esittelyteksti:"Max Weberin"Kaupunki"-kirjan taustasta ja tiedonintressistä", mt., s. 11-21.

2. Georg Simmel,"Suurkaupunki", kokoelmassa Suurkaupunki ja moderni elämä. Kirjoituksia vuosilta 1895-1917. Gaudeamus, 2005. Arto Noron "Esipuhe suomennosvalikoimaan" mt., s. 7-24.

3. Chuck Dyke, The Evolutionary Dynamics of Complex Systems. A Study in Biosocial Complexity, Oxford UP, 1988. Dyken analyysin olennaisia taustoja ovat Jane Jacobs kaupunkiteoreetikkona sekä historioitsijat Fernand Braudel ja Carlo Cipolla.

4. Geoffrey West, Scale. The Universal Laws of Life and Death in Organisms, Cities and Companies. Weidenfeld \& Nicholson, 2017. Westin teoksen otsikko on mahtipontinen, kuten on osittain sisältökin, mutta ärsyyntyminen kannattaa niellä: teos on erinomainen johdatus skaalauksen ongelmiin.

5. Fyysikoiden käyttämä tekninen termi on sub-linear scaling, eli "sub-lineaarinen skaalautuminen". Lineaarinen suhde sen sijaan tarkoittaisi, että koko ja energiantarve kasvaisivat samantahtisesti: norsu tarvitsisi 10,000 kertaa enemmän energiaa kuin hiiri. Koon kasvu vähentää kulutusta per painoyksikkö: vähemmällä enemmän.

6. Allometrian mekanistiset säännönmukaisuudet ovat teknisesti hankalia mutta periaatteiltaan sangen yksinkertaisia. West antaa lähdeviitteet tutkimusryhmänsä tärkeimpiin julkaisuihin. Myös John Whitfield, In the Beat of a Heart. Life, Energy, and the Unity of Nature (Joseph Henry Press, 2006) esittää hyvän yhteenvedon energiaperustaisesta allometriasta.

7. West, mt. Kuviot 34-38, s. 276-277.

8. Simmel, mt., s. 39-40.

9. http://www.riihimaki.fi/kirjasto/rmkkaunokirjallisuus/riihimaen-kuusitoista-vuosikymmenta/1850-luku/

10. Pertti Haapala, "Tampere maailmanhistoriassa", teoksessa Tammerkoski ja kosken kaupunki (Mari Lind, Kimmo Antila \& Antti Liuttunen, toim., Tampereen museot, 2011, s. 54-69).

11. https://www2.pori.fi/pori-info/historia/1972.html

12. Mielenkiintoinen osoitus tästä on se, että Anja Kervanto Nevanlinnan historiikki Voimat jotka rakensivat Helsinkiä 1945-2010 (Otava, 2012) ei tunnista rakennemuutosta lainkaan.

13. Janne Toivonen, Pori-Kirja, Satakunnan Kirjateollisuus Oy, 2008, s. 34-35. Toivonen kommentoi myös Porin yliopistotarinaa ja toteaa, että sen tausta on epäluotettava mutta se voi hyvin olla tosikin. Olennaista on, että yliopistolaitoksen laajentuessa 1960-70-luvulla menestyneet kaupungit kuten Oulu, Joensuu, Kuopio ja Lappeenranta olivat ajaneet asiaa johdonmukaisesti ja pitkään - Pori sen sijaan ei.

14. Jouni Yrjänä, Paloheimo. Neljän sukupolven monialayritys, WSOY, 2007. Teos antaa suvun liikkeenjohdollisista kyvyistä masentavan kuvan.

15. Joseph Schumpeter,"Luovan tuhon prosessi”, Tiede Eंedistys 1/2009, s. $40-45$ (katkelma teoksesta Capitalism, Socialism, Democracy, suomentanut Markku Koivusalo).

16. Erno Paasilinna, Tähänastisen elämäni kirjaimet, Otava 1996, s. 161. 